\title{
CONGENITAL APLASIA OF THE CRUCIATE LIGAMENTS
}

\author{
A REPORT OF SIX CASES \\ ANDRÉ KAELIN. PAUL HENRI HULIN, HENRI CARLIOZ
}

From L'Hôpital Trousseau, Paris

\begin{abstract}
Instability of the knee is frequently found in association with congenital leg-length discrepancy. We have studied six such patients clinically, radiologically and arthroscopically. Clinical signs of knee instability and significant radiological changes were present in all, and at arthroscopy the anterior cruciate ligament was completely absent in four patients and functionless in the other two. This deficiency appears to be a congenital condition which may predispose to meniscus injury or retropatellar pain; it may also lead to subluxation or dislocation of the knee during leg-lengthening procedures.
\end{abstract}

Congenital absence of the cruciate ligaments has been described in association with congenital leg-length discrepancy (Carlioz 1978; Johansson and Aparisi 1982) and other anomalies (Thomas, Jackson and Aichroth 1985). We describe the clinical, radiographic and arthroscopic findings in a further six cases.

\section{PATIENTS AND RESULTS}

Between 1980 and 1982 six patients suffering from congenital leg-length discrepancy with clinical signs of instability of the knee were studied. Four patients also had tarsal coalition. There were two males and four females with ages ranging from 9 to 22 years. In three patients femoral lengthening had been performed using the Wagner technique and one patient was awaiting lengthening: the other two patients did not require surgical lengthening.

The indication for arthroscopy was a locked knee following sporting injury in two patients, retropatellar pain in two, the evaluation of knee instability in one and evaluation before lengthening of the femur in one.

None of the patients complained of instability of the knee but some positive clinical signs were present in all cases, with a positive anterior drawer sign in all six. The posterior drawer sign and the jerk test were positive in five of the six and Lachman's sign was positive in three patients. Significant anterolateral rotatory instability

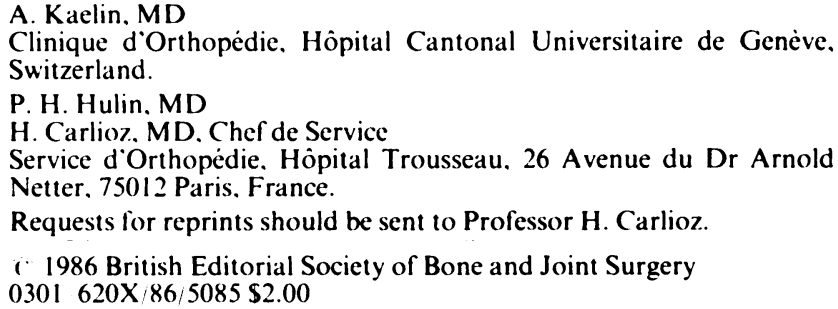

was found in five cases and anteromedial instability in three. In full extension (or minor recurvatum in one patient) only one knee showed any lateral instability to valgus or varus stress.

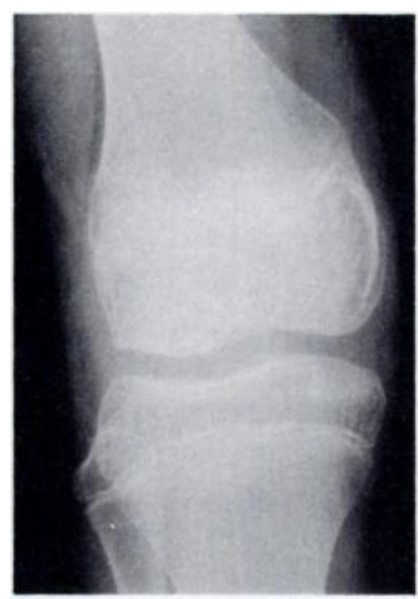

Fig. 1

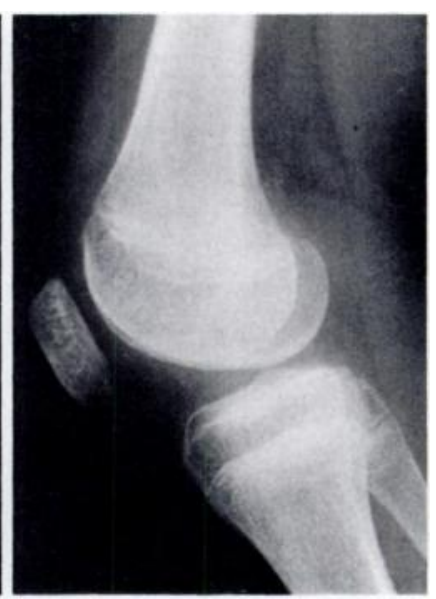

Fig. 2
Radiographs of a case of aplasia of the cruciate ligaments to show the associated changes in bony configuration (see text).

Radiologically, five patients showed valgus deformity with hypoplasia of the lateral femoral condyle (Figs I and 2). This was associated with hypoplasia or aplasia of the intercondylar fossa and flattening of the intercondylar eminence. The patella was small and lateral in three patients and low in two patients.

On arthroscopy the anterior cruciate ligament was completely absent in four patients. In two patients it was represented by a synovial band which was shown by palpation with a meniscal hook not to function as a ligament. The posterior cruciate ligament was completely absent in four of the patients, and present but hypoplastic in one. while in the sixth patient it had an abnormally anterior tibial insertion and was therefore functionless. 


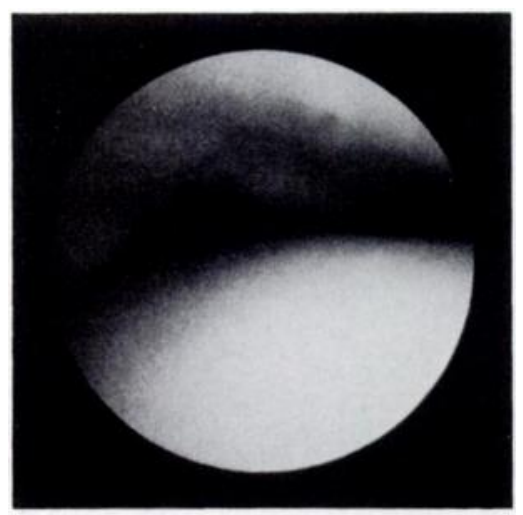

Fig. 3

Arthroscopic photograph and diagram of the intercondylar region in a calse of aplasia of the cruciate ligaments.
The tibial spines were totally absent in two patients and although there were small osseous crests or a central osseous dome in the other four patients (Figs 3 and 4). these had no ligamentous attachments.

Bucket handle tears of the medial meniscus were seen in two knees and were treated arthroscopically. Two knees appeared to have normal menisci and in one the lateral meniscus was hypermobile. In one knee no menisci were found, and the articular surfaces appeared to be flat in the weight-bearing zone. Two cases showed some retropatellar chondromalacia.

\section{DISCUSSION}

Congenital absence of the cruciate ligaments can result in posterior subluxation or dislocation of the knee during surgical lengthening of the femur. The knee must therefore be observed carefully during lengthening to avoid this complication.

The state of the cruciate ligaments can be evaluated before leg lengthening by arthroscopy, and hamstring lengthening may be indicated to prevent posterior subluxation or dislocation. All of our patients appeared to have adapted to their knee instability, though a tear of the medial meniscus. a classic complication of chronic anterior cruciate laxity, was present in two patients. Children with absent cruciate ligaments are at risk of this complication since they lock the knee in extension to provide stability when walking. This may also give rise to retropatellar pain.
The question of the possible surgical stabilisation of such knees is difficult, as the patients do not complain of a sense of instability. In one of our patients an extraarticular ligamentoplasty by the Lemaire technique (1978) was performed at the time of arthroscopic meniscectomy. Postoperatively the knee was much more stable to physical examination but there was no change in subjective assessment. Another patient, who had arthroscopic meniscectomy without ligamentoplasty, had no later complaints of either knee instability or pain.

Conclusion. Anteroposterior and rotatory instability of the knee is frequently found in association with congenital leg-length discrepancy. In our six cases the cruciate ligaments were either congenitally absent or functionless. These patients may develop posterior subluxation or dislocation of the knee during leg-lengthening procedures, and may also be at risk of developing meniscus lesions and significant retropatellar pain.

\section{REFERENCES}

Carlioz H. Symposium sur les grandes hypoplasies et aplasies: description et histoire naturelle des grands aplasies des membres infëricurs. (hir Pediatr 1978:19:306 21

Johansson E, Aparisi T. Congenital absence of the cruciate ligaments: a case report and review of the literature. Clin Orthop 1982:162: 10811

Lemaire .1. Plastic ligamentaire pour rupture ancienne du ligament croise anterieur. Techniques orthopediques. Vol 14. Paris: Expansion Scientificue. 1978.

Thomas NP. Jackson AM, Aichroth PM. Congenital absence of the anterior cruciate ligament. J Bonc Joint Surg $[\mathrm{Br}]$ 1985:67 B: 5725 . 